Available online on 15.02 .2020 at http://jddtonline.info
Open Access to Pharmaceutical and Medical Research
unrestricted non-commercial use, provided the original work is properly cited

Open? Access

Review Article

\title{
Physostigmine: A Plant Alkaloid Isolated from Physostigma venenosum: A Review on Pharmacokinetics, Pharmacological and Toxicological Activities
}

Gaber El-Saber Batiha',2,*†, Luay M. Alkazmi ${ }^{3}$, Eman H. Nadwa ${ }^{4,5}$, Eman K. Rashwan 6,7, Amany Magdy Beshbishy ${ }^{1 \dagger}$, Hazem Shaheen ${ }^{2}$, Lamiaa Wasef ${ }^{2}$

${ }^{1}$ National Research Center for Protozoan Diseases, Obihiro University of Agriculture and Veterinary Medicine, Nishi 2-13, Inada-cho, 080-8555, Obihiro, Hokkaido, Japan

${ }^{2}$ Department of Pharmacology and Therapeutics, Faculty of Veterinary Medicine, Damanhour University, Damanhour 22511, AlBeheira, Egypt

${ }^{3}$ Biology Department, Faculty of Applied Sciences, Umm Al-Qura University, Makkah 21955, Saudi Arabia

${ }^{4}$ Department of Pharmacology and Therapeutics, College of Medicine, Jouf University, Sakaka, Saudi Arabia

${ }^{5}$ Department of Medical Pharmacology, Faculty of Medicine, Cairo University, Egypt

${ }^{6}$ Department of Physiology, College of Medicine, Al-Azhar University, Assuit, Egypt

${ }^{7}$ Department of Physiology, College of Medicine, Jouf University, Sakaka, Saudi Arabia

† These authors contributed equally

\begin{abstract}
Medicinal plants have been documented as an important source for discovering new pharmaceutical molecules that have been used to treat serious diseases. Strikingly, previous reports stated that natural products and their derived compounds exhibit lesser side effects and improved efficacy than other synthetic counterparts. Physostigmine, a parasympathomimetic plant alkaloid isolated from the West African perennial shrub Physostigma venenosum, it shows a narrow therapeutic index and a short life span, despite its ability to penetrate the blood-brain barrier (BBB). It is a widely known reversible butyrylcholinesterase (BuChE) and acetylcholinesterase (AChE) inhibitor and has been document ed to treat various ailments such as Alzheimer's disease. Pharmacologically, physostigmine was first reported as an antidote for atropine scopolamine and belladonna alkaloids toxicity. Recently, it has been documented as a therapy for treating several ailments including glaucoma, myasthenia gravis and the intoxication caused by tricyclic antidepressant overdoses, anti-histamines, antipsychotics, and benzodiazepines. Physostigmine has been reported to be absorbed from the gastrointestinal tract and showed short half-life, as, after the oral administration of 2 mg of physostigmine salicylate, the peak plasma concentration reached to 30 minutes. This review examines the biological activities, pharmacokinetics, and toxicity of physostigmine extracted from $P$. venenosum.
\end{abstract}

Keywords: Physostigma venenosum, Physostigmine, pharmacological activities, acetylcholinesterase and butyrylcholinesterase inhibitor.

Article Info: Received 19 Nov 2019; $\quad$ Review Completed 14 Jan 2020; $\quad$ Accepted 23 Jan 2020; Available online 15 Feb 2020

Cite this article as:

Batiha GE, Alkazmi LM, Nadwa EH, Rashwan EK, Beshbishy AM, Shaheen H, Wasef L, Physostigmine: A Plant Alkaloid Isolated from Physostigma venenosum: A Review on Pharmacokinetics, Pharmacological and Toxicological Activities, Journal of Drug Delivery and Therapeutics. 2020; 10(1-s):187-190 http://dx.doi.org/10.22270/jddt.v10i1-s.3866

\section{*Address for Correspondence:}

Gaber El-Saber Batiha, DVM, PhD, Department of Pharmacology and Therapeutics, Faculty of Veterinary Medicine, Damanhour University, Damanhour 22511, AlBeheira, Egypt

\section{INTRODUCTION}

Physostigmine, a parasympathomimetic plant alkaloid isolated from Physostigma venenosum, the famous West African perennial shrub and it shows a narrow therapeutic index and a short life span, despite its ability to penetrate the blood-brain barrier (BBB) [1]. Moreover, physostigmine has been extracted from Streptomyces pseudogriseolus cultures. Physostigmine acts by interfering with the metabolism of acetylcholine (ACh) (Fig 1). It is a covalent (reversible-bond hydrolyzed and released) butyrylcholinesterase (BuChE) and acetylcholinesterase (AChE) inhibitor in the plasma, erythrocytes, and brain; AChE is the enzyme that is responsible for the ACh breakdown in the synaptic cleft of the neuromuscular junction [2] and it acts by indirect stimulation of nicotinic as well as muscarinic ACh receptors. 


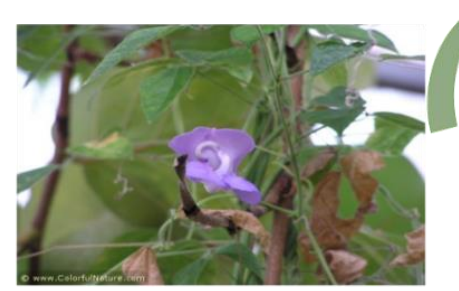

Physostigma venenosum

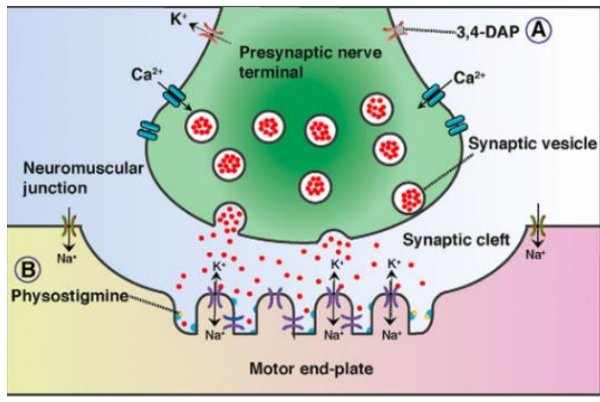

Accumulate at the muscarinic or nicotinic receptors at the synapse sites

- Promoting the muscarinic, nicotinic and CNS activities<smiles>CNC(=O)Oc1ccc2c(c1)C1(C)CCN(C)C1(C)C2(C)C</smiles>

Physostigmine

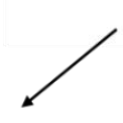

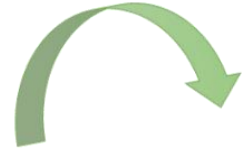

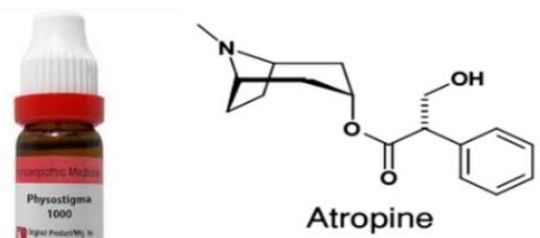

Atropine

First reported as an antidote of atropine poisoning

Figure 1: The pharmacological activities of physostigmine

Initially, physostigmine was reported as a remedy for atropine poisoning [3]. Nowadays, it has been documented as a therapy for the treatment of several ailments including glaucoma, myasthenia gravis [4], atropine, scopolamine, and belladonna alkaloids intoxication [5], and the intoxication caused by tricyclic antidepressants overdoses [6], antihistamines [7], antipsychotics [8], and benzodiazepines [4], Physostigmine also possesses an important role as a significant protective compound toward organophosphate poisoning by binding with the active groups in AChE reversibly [9],

\section{CHEMICAL STRUCTURE}

Physostigmine (Fig 2; $\mathrm{C}_{15} \mathrm{H}_{21} \mathrm{~N}_{3} \mathrm{O}_{2}$ ) a lipid-soluble tertiary ammonium compound that has a pKa value of 7.9 and easily ionized in the $\mathrm{pH}$ of the brain and blood [10]. The following physostigmine structure was first detected in 1925 (1,2,3,3a,8,8a-hexahydro-1,3a,8-trimethyl-pyrrolo[2,3b]indo-5-ol-methylcarbamate) [4].<smiles>CNC(=O)Oc1ccc2c(c1)[C@]1(C)CCN(C)[C@H]1N2C</smiles>

Figure 2: Chemical structure of physostigmine

\section{PHYSOSTIGMINE SYNTHESIS}

Synthetically, physostigmine has been synthesized by different methods, one of them performed in the presence of aluminum chloride by the reaction of $\alpha$ bromopropionyl bromide with $p$-ethoxymethylaniline resulting in 1,3-dimethyl-5-ethoxyindolin-2-one. Afterward, in the presence of sodium ethoxide, chloracetonitrile reacts with 1,3-dimethyl-5-ethoxyindolin-2-one and results in 1,3dimethyl-5-ethoxy-3-cyanomethylindolin-2-one.

The nitrile group reduction to amine group has occurred that is additionally methoxided and resulted in 1, 3-dimethyl-5ethoxy-3-( $\beta$ methylaminoethyl) indolin-2-one. After that, the carbonyl group reduction is occurred to form amino alcohol by which its dehydration results in 1,3a,8-trimethyl2,3,3a,8a-tetrahydropyrrolo[2,3b]-5-ethoxyindol formation. The hydrogen bromide was used to remove the ethoxyprotecting group resulting in a compound containing a phenol hydroxyl group that is further reacted with methyl isocyanate to give physostigmine [11].

\section{PHARMACOKINETICS}

Physostigmine has been documented to be absorbed from the gastrointestinal tract and other mucous membranes with an oral bioavailability between (1-8\%) [12]. Physostigmine has been documented to show short half-life, as after the oral administration of $2 \mathrm{mg}$ of physostigmine salicylate, the peak plasma concentration reached to 30 minutes, whereas after oral administration of $4 \mathrm{mg}$, the peak serum levels reached to 45 minutes and become undetectable within 3 hours [12,13]. Once physostigmine enters the blood circulation, it penetrates the BBB smoothly and subsequently inactivated by the plasma cholinesterase. Additionally, physostigmine is metabolized rapidly from the body due to the presence of plasma esterase that leads to its hydrolytic cleavage at the ester bond and, consequently, results in the loss of its pharmacological activity $[14,15]$. Physostigmine has been documented to be used as an antidote for anticholinergic toxicity of antihistamines, atropine, tricyclic antidepressants, and phenothiazine because of its ability to spread to the central nervous system (CNS) [16].

\section{MECHANISM OF ACTION OF PHYSOSTIGMINE}

Physostigmine, a cholinergic drug that acts by inhibiting the AChE and BuChE enzymes that break down acetylcholine, thus increasing ACh amounts at cholinergic synapsis in the central and peripheral nervous systems and, consequently, 
accumulate at the muscarinic or nicotinic receptors at the synapse sites and promoting the muscarinic, nicotinic and CNS activities [17]. Regarding the muscarinic receptor effects, physostigmine causes increased urination and aqueous humor production, decreased pupil size, increased salivation, increased the secretions of the gastrointestinal tract, and sweating [18]. Nicotinic effects are those influencing sympathetic ganglia or striated muscle such as fasciculation, cramps, high blood pressure, twitching, tachycardia, and weakness [19], while convulsions, ataxia, and coma are those of the CNS effects symptoms [18].

\section{ALZHEIMER'S DISEASE AND PHYSOSTIGMINE}

Nowadays, AChE is considered the most important molecular target for treating dementia in $\mathrm{AD}$, therefore, acetylcholinesterase inhibitors (AChEIs) are currently considered to be one of two drug categories approved to treat $\mathrm{AD}[20,21]$. All drugs act by promoting the cholinergic deficit, thereby, they reveal the potential efficacy of the behavioral, functional, and cognitive symptoms of $\mathrm{AD}$ [22]. A significant loss in the cholinergic neurons has been observed in the postmortem brains infected with $\mathrm{AD}$, which are widely disseminated in the hippocampus, amygdala, and neocortex [23]. Decreased the cortical choline acetyltransferase efficacy is related to the number of aging plaques and cognitive decline in $\mathrm{AD}$ patients [24]. Physostigmine was the first nonselective reversible $\mathrm{AChE}$ and BuChE inhibitor investigated for treating $\mathrm{AD}$ [1], thus increasing central cholinergic neurotransmission. In the in vivo experiments, physostigmine enhances memory in elderly primates [25], as well as primates with amnesia caused by scopolamine, whereas in clinical trials physostigmine has shown improved cognitive function in patients with AD [26].

\section{Combination Therapy of Physostigmine with Drugs against Alzheimer's disease}

Nowadays, combination chemotherapies are being reported to alleviate serious diseases, including pulmonary tuberculosis, malignancy, immune deficiency syndrome, AD, and some protozoal diseases to promote higher therapeutic efficacy [27-30]. Schmitt et al. [31] documented the combined effect of selegiline with AChE inhibitors such as physostigmine or tacrine in AD patients, as well as AChE inhibitor and $\alpha$-lipoic acid AChE inhibitors are very likely to be part of any AD combination regimen [32].

\section{DOSE}

Recently, Orhan et al. [1] investigated that physostigmine has an $\mathrm{LD}_{50}$ of $3 \mathrm{mg} / \mathrm{kg}$ in mice. Moreover, Van Dyck et al. [33] documented that slow-release physostigmine salicylate at 18 , 24 , and $30 \mathrm{mg} /$ day could be a potential and safe drug for treating $\mathrm{AD}$ for 6 weeks. The recommended adult dose is ranged from 0.5 to $2 \mathrm{mg}$ [34], while Kaye. [35] revealed the minimal lethal dose of physostigmine to be $60 \mathrm{mg} / 70$ $\mathrm{kg} /$ person and its chemotherapeutic blood level is ranged from 0.001 to $0.01 \mathrm{mg} / \mathrm{L}^{\text {[36] }}$.

\section{TOXIC SIDE EFFECTS}

Physostigmine, an AChE inhibitor, which stimulates ACh hydrolysis to choline and acetic acid. Therefore, physostigmine can produce acute toxic effects and it can cause muscarinic receptor stimulation including nausea, vomiting, diarrhea, abdominal pain, respiratory tract secretions, hypersalivation, seizures, Diaphoresis, Tachycardia, blurred vision, bradycardia and atrial fibrillation [37]. Additionally, it led to the stimulation of nicotinic receptors, inducing paralysis, weakness, muscle twitching and stimulation of cholinergic receptors in the CNS followed by CNS depression, convulsions, coma, and finally death. The short plasma half-life and the first-pass metabolism of physostigmine inhibited its clinical use in treating AD. Therefore, to overcome this problem, novel slow-release physostigmine salicylate (Synapton) preparation was developed to produce sustainable blood levels [33, 38].

To be noted, death resulted from physostigmine overdose is commonly attributed to pulmonary edema and/or failure of respiration and the duration of death is ranged between 5 min-24 $\mathrm{h}$ based on the physostigmine dose and route of administration [15]. Recently, synthetic physostigmine derivatives such as phenserine and eptastigmine have been developed and they revealed strong inhibition of AChE and demonstrated improved cognitive functions in preclinical and clinical studies by indirect stimulation of nicotinic as well as muscarinic ACh receptors [21]. Moreover, heptyl physostigmine, the physostigmine salt form, which showed higher lipophilicity, less toxicity than physostigmine while maintaining AChE inhibitor property and it can pass easily through BBB. Its use has been reported in the treatment of the CNS symptoms caused by scopolamine, atropine and other anticholinergic overdoses [34].

\section{CONTRAINDICATIONS}

Physostigmine was contraindicated in patients with hyperthyroidism, angle-closure glaucoma, hypotension, asthma, diabetes, vagal tone increase, gastrointestinal or urogenital tract obstruction, gastroesophageal reflux disorder, bradycardia, gangrene, peptic ulcer, cardiovascular and seizure disorders. Moreover, it is contraindicated to be administered with choline esters and depolarizing neuromuscular blockers or a salicylate/sulfite allergy [18]. Furthermore, it is contraindicated for patients with QRS prolongation on electrocardiogram or those with a history of QRS medication overdose [37].

\section{CONCLUSION}

Physostigmine, a lipid-soluble tertiary amine carbamate plant alkaloid that was first reported as an antidote to atropine toxicity. It is a famous reversible BuChE and AChE inhibitor and it has been used in treating different diseases including $\mathrm{AD}$. The finding that physostigmine can combine with other drugs is a property that can be explored in the chemotherapies development against AD. However, its clinical use as a therapy has been prohibited due to the existence of the toxic side effects and its short half-life, therefore, new synthetic derivatives such as phenserine, eptastigmine, heptyl physostigmine and extended-release formulation of physostigmine salicylate (Synapton) have been developed to produce sustainable blood levels and overcome the above-mentioned problems.

\section{REFERENCES}

[1] Orhan G, Orhan I, Subutay-Oztekin N, et al, Contemporary anticholinesterase pharmaceuticals of natural origin and their synthetic analogues for the treatment of Alzheimer's disease. Recent patents on CNS drug discovery, 2009; 4: 43-51.

[2] Comunián-Carrasco G, Peña-Martí GE, Martí-Carvajal AJ, Antibiotics for treating gonorrhoea in pregnancy. The Cochrane database of systematic reviews, 2018; 2(2): CD011167.

[3] Nickalls RW, Nickalls EA, The first use of physostigmine in the treatment of atropine poisoning. A translation of Kleinwachter's paper entitled 'Observations on the effect of Calabar bean extract as an antidote to atropine poisoning'. Anaesthesia. 1988; 43: 776-779.

[4] Triggle DM, Mitchell J, Filler R, The pharmacology of physostigmine. CNS Drug Reviews, 2006; 4: 87-136.

[5] Singh A, Srivastava PS, Asad M, et al, A review on physostigmine: as antidote and treatment on Alzheimer's 
disease. International Journal of Pharmaceutical and Analytical Research, 2015; 4: 512-517.

[6] Kerr GW, McGuffie AC, Wilkie S, Tricyclic antidepressant overdose: a review. Emergency Medicine Journal, 2001; 18: 236-241.

[7] Lee J-H, Turndorf $\mathrm{H}$ and Poppers PJ, Physostigmine reversal of antihistamine-induced excitement and depression. Anesthesiology, 1975; 43: 683-684.

[8] Beilin B, Vatashsky E, Weinstock M, Physostigmine as an antidote for poisoning by combination of thioridazine and trihexyphenidyl. The British journal of clinical practice, 1985; 39: 400-401.

[9] Lorke DE, Petroianu GA, Reversible cholinesterase inhibitors as pretreatment for exposure to organophosphates. A review. Journal of Applied Toxicology, 2019; 39(1): 101-116.

[10] Somani SM, Pharmacokinetics and pharmacodynamics of physostigmine in the rat after oral administration. Biopharmaceutics \& Drug Disposition, 1989; 10: 187-203.

[11] Morales-Ríos MS, Bucio MA, Joseph-Nathan P, Formal synthesis of $( \pm)$-physostigmine. Tetrahedron. 1996; 52: 53395348.

[12] Walter K, Muller M, Bark worth M, et al, Pharmacokinetics of physostigmine in man following a single application of a transdermal system. The British journal of clinical pharmacology, 1995; 39: 59-63.

[13] Allen N, Burns A, The treatment of Alzheimer's disease. Journal of Psychopharmacology, 1995; 9: 43-56.

[14] Gleason MN, Gosselin RE, Hodge H, et al, Clinical toxicology of commercial products-acute poisoning (home and farm) Paltimore, Md., Williams and Wilkins: 130. Journal of the American Pharmaceutical Association, 1957; 46: 748-748.

[15] Firestone JA, Smith-Weller T, Franklin G, et al, Pesticides and risk of Parkinson disease: a population-based case-control study. Archives of neurology, 2005; 62: 91-95.

[16] Watkins JW, Schwarz ES, Arroyo-Plasencia AM, Mullins ME, Toxicology investigators consortium investigators. The use of physostigmine by toxicologists in anticholinergic toxicity. Journal of Medical Toxicology, 2015; 11(2): 179-184.

[17] Colović MB, Krstić DZ, Lazarević-Pašti TD, Bondžić AM, Vasić VM, Acetylcholinesterase inhibitors: pharmacology and toxicology. Current Neuropharmacology, 2013; 11(3): 315335.

[18] Andrade OA, Zafar Gondal A, Physostigmine. [Updated 2019 Jul 31]. In: StatPearls [Internet]. Treasure Island (FL): StatPearls Publishing; 2019 Jan-. Available from: https://www.ncbi.nlm.nih.gov/books/NBK545261.0

[19] Peter JV, Sudarsan TI, Moran JL, Clinical features of organophosphate poisoning: A review of different classification systems and approaches. Indian Journal of Critical Care Medicine, 2014; 18(11): 735-745.

[20] Folch J, Petrov D, Ettcheto M, Abad S, Sánchez-López E, García ML, Olloquequi J, Beas-Zarate C, Auladell C, Camins A, Current research therapeutic strategies for Alzheimer's disease treatment. Neural Plasticity, 2016; 2016: 8501693.

[21] Giacobini E, Cholinesterase inhibitors: new roles and therapeutic alternatives. Pharmacological Research, 2004; 50: 433-440.

[22] Fang L, Kraus B, Lehmann J, et al, Design and synthesis of tacrine ferulic acid hybrids as multi-potent anti-Alzheimer drug candidates. Bioorganic \& Medicinal Chemistry Letters, 2008; 18: 2905-2909.

[23] Maurer SV, Williams CL, The cholinergic system modulates memory and hippocampal plasticity via its interactions with non-neuronal cells. Frontiers in Immunology, 2017; 8: 1489.

[24] Perry EK, Tomlinson BE, Blessed G, et al, Correlation of cholinergic abnormalities with senile plaques and mental test scores in senile dementia. British medical journal, 1978; 2: 1457-1459.

[25] Bartus RT, Dean RL, Tetrahydroaminoacridine, 3, 4 diaminopyridine and physostigmine: direct comparison of effects on memory in aged primates. Neurobiology of Aging, 1988; 9: 351-356.

[26] Dhingra D, Kumar V, Memory-enhancing activity of palmatine in mice using elevated plus maze and Morris water maze. Advances in Pharmacological Sciences, 2012; 2012: 357368.

[27] Batiha GE-S, Beshbishy AA, Tayebwa DS, Shaheen MH, Yokoyama N, Igarashi I, Inhibitory effects of Uncaria tomentosa bark, Myrtus communis roots, Origanum vulgare leaves and Cuminum cyminum seeds extracts against the growth of Babesia and Theileria in vitro. Japanese Journal of Veterinary Parasitology, 2018; 17: 1-13.

[28] Batiha GE-S, Beshbishy AM, Tayebwa DS, Adeyemi OS Shaheen H, Yokoyama N, et al, The effects of trans-chalcone and chalcone 4 hydrate on the growth of Babesia and Theileria. PLoS Neglected of Tropical Disease, 2019a; 13: e0007030.

[29] Beshbishy AM, Batiha GE, Yokoyama N, Igarashi I, Ellagic acid microspheres restrict the growth of Babesia and Theileria in vitro and Babesia microti in vivo. Parasits and Vectors, 2019a; 12: 269.

[30] Batiha GE-S, Beshbishy AA, Tayebwa DS, Shaheen MH, Yokoyama N, Igarashi I, Inhibitory effects of Syzygium aromaticum and Camellia sinensis methanolic extracts on the growth of Babesia and Theileria parasites. Ticks and Tickborne Disease, 2019b; 10: 949-958.

[31] Schmitt B, Bernhardt T, Moeller H-J, et al, Combination therapy in Alzheimer's disease. CNS Drugs, 2004; 18: 827-844.

[32] Hager K, Marahrens A, Kenklies M, et al, Alpha-lipoic acid as a new treatment option for Alzheimer type dementia. Archives of Gerontology and Geriatrics, 2001; 32: 275-282.

[33] Van Dyck CH, Newhouse P, Falk WE, et al, Extended-release physostigmine in Alzheimer disease: a multicenter, doubleblind, 12-week study with dose enrichment. Archives of General Psychiatry, 2000; 57: 157-164.

[34] Sahoo AK, Dandapat J, Dash UC, Kanhar S, Features and outcomes of drugs for combination therapy as a multi-targets strategy to combat Alzheimer's disease. Journal of Ethnopharmacology, 2018; 215: 42-73.

[35] Kaye S, Handbook of emergency toxicology: a guide for the identification, diagnosis and treatment of poisoning. 5th ed. Charles C Thomas Pub Ltd, 1970; 1988: 31-44.

[36] Hartvig P, Lindström B, Pettersson E, et al, Reversal of postoperative somnolence using a two-rate infusion of physostigmine. Acta Anaesthesiologica Scandinavica, 1989; 33: 681-685.

[37] Arens AM, Kearney TJ, Med, Adverse Effects of Physostigmine. Toxicology, 2019; 15: 184.

[38] Coelho F and Birks J, Physostigmine for Alzheimer's disease. Cochrane database of systematic reviews, 2001; (2): CD001499. 